\title{
História e crítica em direito internacional na América Latina: revisitando discussões pretéritas sobre ensino jurídico na região ${ }^{* *}$
}

\section{History and critique in International Law in Latin America: Revisiting past discussions on legal education in the region}

RESUMO

Este trabalho tem como objetivo revisitar os questionamentos articulados no âmbito das cinco Conferências de Faculdades de Direito Latino-Americanas realizadas entre 1959 e 1974 em nossa região. Sem pretender uma reconstrução histórica exaustiva sobre esses encontros, este estudo busca lançar luz em antigas discussões sobre ensino jurídico na América Latina. De forma semelhante, não se busca discutir o quanto efetivamente foi alterado na organização e nas atividades das faculdades de direito a partir das recomendações adotadas nas

Pesquisadora em nível de Pós-Doutorado no Laureate Program in International Law, Faculdade de Direito da Universidade de Melbourne (www.lpil.org). Doutora (2012) e mestre (2006) em Direito Internacional pela Universidade de São Paulo (USP), Brasil. Correio eletrônico: fabia.vecoso@gmail.com

Meus agradecimentos aos amigos e membros do projeto REDIAL Amaya Álves Marín, Enrique Prieto-Ríos, Laura Betancur Restrepo, Paola Andrea Acosta Alvarado e Jimena Sierra-Camargo por todo o aprendizado e pelas conversas substantivas sobre o ensino e a pesquisa do direito internacional na América Latina. As incorreções e erros deste trabalho são de minha inteira responsabilidade.

Postdoctoral Fellow with the Laureate Program in International Law, Melbourne Law School. Ph.D. (2012) and LL.M. (2006) in International Law, State University of São Paulo (USP), Brazil. Electronic address: fabia.vecoso@gmail.com

Special thanks to my friends and REDIAL colleagues Amaya Álves Marín, Enrique PrietoRíos, Laura Betancur Restrepo, Paola Andrea Acosta Alvarado e Jimena Sierra-Camargo for all substantive exchanges and insights on international legal education in Latin America. The usual disclaimer applies.

** Recibido el 8 de febrero de 2017, aprobado el 19 de abril de 2017.

Para citar el artículo: Fernandes Carvalho Veçoso, F. História e crítica em direito internacional na América Latina: revisitando discussões pretéritas sobre ensino jurídico na região. Derecho del Estado n. ${ }^{\circ}$ 39, Universidad Externado de Colombia, julio-diciembre de 2017, 91-117. DOI: https://doi.org/10.18601/01229893.n39.05 
referidas conferências, mas sim explorar questionamentos pretéritos sobre o papel do direito em projetos políticos de transformação. A retomada dessas discussões é importante para embasar reflexões inovadoras sobre o ensino do direito internacional na América Latina na atualidade, pois mudanças foram propostas a partir de uma sensibilidade latino-americana, revelando-se a necessidade de atrelar projetos políticos a iniciativas de reforma pedagógica. Considerando que estudos históricos em direito internacional necessariamente contém um certo elemento de anacronismo, tal como afirmado por Anne Orford em ¿El passado como derecho o como historia? La relevância del imperialismo para el derecho internacional moderno, esta contribuição aborda a dimensão histórica dos debates sobre ensino jurídico na América Latina como esforço necessário para as reflexões empreendidas atualmente no contexto do projeto "Repensar la educación en derecho internacional en América Latina" (REDIAL).

PALAVRAS-CHAVE

Conferências de Faculdades Latino-Americanas de Direito, ensino do direito internacional, América Latina, história do direito internacional, estudos críticos.

\section{ABSTRACT}

This contribution revisits the discussions undertaken between 1959 and 1974 during the holding of the five Conferences of Latin American Law Schools in our region. With no intention to present a comprehensive historical reconstruction of these meetings, this study aims at shedding light on past dialogues on legal education in Latin America. In a similar vein, this contribution will not discuss how effectively the recommendations reached at these meetings have changed the organization and the activities of Latin American law schools, but it will explore past interrogations on the role of law in political projects of transformation. The resumption of these discussions is important to support innovative reflections on international legal education in Latin America today because changes were proposed based on a Latin American sensibility, revealing the need to link political projects to pedagogical reform initiatives. Considering that historical studies in international law are necessarily anachronistic, as stated by Anne Orford in The past as law or history? The relevance of imperialism for modern international law, this contribution approaches the history of discussions on legal education in Latin America as a necessary effort related to the current interrogations articulated in the context of the project "Rethinking International Legal Education in Latin America" (REDIAL). 


\section{KEYWORDS}

Conferences of Latin American Law Schools, international legal education. Latin America, history of International Law, critical approaches.

\section{SUMÁRIO}

Introdução. 1. Direito internacional e história: considerações sobre os usos de textos do passado pelo jurista internacionalista. 2. Conferências de Faculdades de Direito Latino-Americanas: breves notas. 3. A ideia regional: oportunidade de desenvolvimento de estudos críticos em direito internacional na América Latina hoje? Considerações finais. Referências.

19. - En los planes de estudio, debe propenderse a la orientación de las materias hacia lo latinoamericano, citándose por vía de ejemplo, los seguintes estudios, que no constituirán necesariamente cátedra especial: Derecho Internacional Latinoamericano, Historia del Derecho Aborigen, Indiano y Patrio de la América Latina; Sociología Jurídica Latinoamericana, Derecho Económico Latinoamericano, Derecho Aeronáutico Latinoamericano, Derecho Político Americano, Derecho Administrativo Latinoamericano. Esta preocupación podrá ser satisfecha através de institutos interamericanos.

Declaración de Principios y Recomendaciones sobre la Enseñanza del Derecho (Ciencias Políticas y Sociales) en América Latina, Primeira Conferência de Faculdades de Direito Latino-Americana, México, $1959^{[1]}$.

LA TERCERA CONFERENCIA, Acuerda:

Recomendar que dentro de los estudios e investigaciones de contenido socioeconómico, se de preferencia a los Problemas de Desarrollo, particularmente, en sus relaciones con los factores institucionales y sociales, atendida la circunstancia de que estos condicionan el proceso mismo de desarrollo.

Que para lograr el objetivo señalado en el número anterior, debe realizarse por las

Facultades de Derecho Latinoamericanas, una revisión de los planes y programas de estudio, a fin de renovar su contenido e imprimirles el sentido dinámico que es de la esencia del Desarrollo. Igual criterio debe adoptarse con respecto de la investigación universitaria.

Acuerdos de Plenarios sobre la sección III: Misión de las Facultades de Derecho;

Tema III, B, 1: Problemática institucional del desarrollo, Terceira Conferência de Faculdades de Direito Latino-Americanas,

Chile, $1963^{[2]}$.

1 Primera Conferencia de Facultades/Escuelas Latinoamericanas de Derecho (Ciencias Jurídicas y Sociales). Informes. Revista de la Facultad de Derecho de México. V. 9. N. 33-34, enero-junio, 1959, 451.

2 Tercera Conferencia de Facultades (Escuelas) de Derecho (Ciencias Jurídicas, Políticas y Sociales) Latinoamericanas. Facultad de Ciencias Jurídicas y Sociales, Universidad de Chile, $1964,835$. 


\section{INTRODUÇÃO}

Os trechos reproduzidos acima ilustram parte dos debates realizados no âmbito das conferências de faculdades de direito latino-americanas realizadas durante a segunda metade do século xx em diversos países da região. Como é possível compreender a partir da leitura desses trechos, afirmou-se a necessidade de articulação de uma sensibilidade latino-americana no contexto das atividades das faculdades de direito. De forma ainda mais relevante, as reformas pedagógicas orientadas "hacia lo latinoamericano" estiveram relacionadas às intensas discussões sobre desenvolvimento e modernização dos países latino-americanos verificadas entre os anos cinquenta e setenta do século passado, temática que orientou muitos dos debates acadêmicos nas ciências sociais da região à época, como será visto com mais detalhes neste estudo.

Em cinco ocasiões entre 1959 e $1974^{[3]}$, professores, pesquisadores, estudantes e advogados da América Latina, juntamente com participantes observadores de outros países, além de acadêmicos e profissionais de áreas correlatas, reuniram-se para repensar o ensino jurídico da região orientados por uma perspectiva bastante particular: por meio de uma sensibilidade latino-americana, os participantes das conferências de faculdades de direito latino-americanas buscaram não apenas reformular e uniformizar planos de ensino de cursos de direito, mas associar os debates pedagógicos do campo às questões relacionadas às condições estruturais que possibilitariam o desenvolvimento da região. A faculdade de direito foi vista, assim, como espaço implicado nas possibilidades transformadoras relacionadas a uma região que buscava deixar para trás a condição de subdesenvolvida.

Essas conferências foram realizadas contando com o apoio da União de Universidades Latino-Americanas. Criada em 1949 no âmbito do Primeiro Congresso de Universidades Latino-Americanas realizado pela Universidad de San Carlos de Guatemala ${ }^{4}$, a União de Universidades da América Latina e do Caribe (UDUAL), como chamada atualmente, é uma organização não governamental que possui status consultivo junto à Organização das Nações Unidas para a Educação, Ciência e Cultura (UNESCO) $)^{5}$. De forma geral, a UDUAL se estabeleceu em 1949 em um contexto marcado pela busca de intercâmbio e cooperação acadêmica entre universidades de todo o mundo ${ }^{6}$. Apenas para

3 Pérez-Perdomo, R. Latin American Lawyers: A Historical Introduction. Stanford, Stanford University Press, 2006, 110; FiX-Zamudio, H. Algunas reflexiones sobre la enseñanza del derecho en México y Latinoamérica. In Witker Velásquez, J. A. (comp.). Antología de estudios sobre la enseñanza del derecho. México: unAm, 1995, 77-92.

$4 \quad$ Universidad Nacional Autónoma de México. El Primer Congresso de Universidades Latinoamericanas. Revista de la Universidad de México. V. 3. N. 34, 1949, 1.

5 Página eletrônica da UDUAL: https://www.udual.org/ Acesso em 29 de janeiro de 2017.

6 Burbano López, G. La Unión de Universidades de América Latina y el Caribe (UdUAL) y la autonomia universitaria. Ciencia Política. N. 12, 2011, 149. 
ilustrar, em 1950 foi criada a Associação Internacional de Universidades (AIU), organização não governamental de escopo global com sede em Paris e que atualmente é uma organização afiliada à UNESCO ${ }^{7}$. De forma específica, a UDUAL se estabeleceu em um momento de intensas reflexões sobre o papel das universidades na região, em um contexto fortemente informado pelos debates sobre teorias da modernização e desenvolvimento da América Latina ${ }^{8}$.

Este trabalho tem como objetivo revisitar os questionamentos articulados no âmbito das Conferências de Faculdades de Direito Latino-Americanas realizadas entre 1959 e 1974. Sem pretender uma reconstrução histórica exaustiva sobre esses encontros de faculdades de direito da nossa região, este estudo busca lançar luz em antigas discussões sobre ensino jurídico na América Latina. Interessa-me mais os questionamentos e interrogações articuladas pelos delegados participantes, do que propriamente um mapeamento exaustivo dos debates e dos resultados concretos alcançados a partir desses encontros. Assim, este trabalho não busca discutir o quanto efetivamente foi alterado na organização e nas atividades das faculdades de direito da América Latina a partir das recomendações adotadas nas conferências, mas sim buscar revisitar questionamentos pretéritos sobre o papel do direito em projetos políticos de transformação. A retomada dessas discussões é importante para embasar reflexões inovadoras sobre a prática, o ensino e a pesquisa do direito internacional na América Latina na atualidade, pois mudanças foram propostas a partir de uma sensibilidade latino-americana, revelando-se a necessidade de atrelar projetos políticos a iniciativas de reforma pedagógica. Portanto, para além de uma reconstrução histórica e exaustiva desses encontros, interessa-me relembrar como advogados latino-americanos passaram a interrogar seu próprio campo no âmbito de um contexto de intensos debates teóricos nas Ciências Sociais em matéria de desenvolvimento e modernização da região9

7 Página eletrônica da AIU: https://www.iau-aiu.net Acesso em 31 de março de 2017.

8 SiERra, L. Derecho, cambio social y los juristas en Chile: de la estridencia de los 60 al silencio de hoy. Y(2002). SELA (Seminario en Latinoamérica de Teoría Constitucional y Política) Papers. Paper 13, in: http://digitalcommons.law.yale.edu/yls_sela/13; Pérez-Perdomo. Latin American Lawyers, cit., 99-136; OCAMPO LóPEZ, J. Darcy Ribeiro: sus ideas educativas sobre la universidad y el processo civilizatorio de América Latina. Historia de la Educación Latinoamericana. V. 8, 2006, 137-160; RibeIRo, D. Darcy Ribeiro (depoimento, 1978). Rio de Janeiro, CPDOC, 2010. Veja também RiBeIRo, D. La Universidad Latinoamericana. Caracas, Biblioteca de la Universidad Central de Venezuela, 1971.

9 As palavras de Lucas Sierra bem resumem esse rico contexto de debates sobre modernização e desenvolvimento: "La idea de modernización era el horizonte conceptual de esa sociedad percibida en curso de cambio. La modernización tiene el más técnico de los sentidos que suelen asociarse a la idea general y abstracta de lo moderno. Usualmente se equipara modernización a desarrollo, y con ambos se aludía a una cierta planificación de la vida social, a una cierta tecnología con la que se deseaba, finalmente, acelerar el tiempo histórico. La modernización era el intento deliberado, bastante racionalista, de hacer calzar un conjunto de valores con las instituciones y prácticas sociales. La modernización era, en el lenguaje de la 
Vale sublinhar que o foco na pedagogia jurídica esteve associado a esse contexto mais amplo de discussões intelectuais sobre reformas estruturais orientadas ao desenvolvimento. Assim, reconheceu-se o papel das universidades como instituições implicadas nesse processo transformador, de forma que reformas universitárias foram defendidas durante os anos sessenta e setenta como condição para o desenvolvimento. Advogados, professores, pesquisadores e estudantes de direito não ficaram alheios a esse contexto e os debates realizados durante as cinco conferências de faculdades de direito latino-americanas refletem esse cenário mais amplo de debates, como ilustram as citações que abrem este trabalho.

É produtivo revisitar os questionamentos realizados durante essas conferências para se pensar atualmente a prática, o ensino e a pesquisa do direito internacional na América Latina, pois a sensibilidade latino-americana que marcou esses encontros colocava ênfase no ensino do direito internacional, em especial o chamado direito internacional latino-americano. Assim, mesmo não sendo encontros exclusivamente focados em direito internacional, essas conferências nos ajudam a repensar a prática contemporânea do direito internacional e as respectivas experiências de ensino e pesquisa por conta da reconhecida importância de uma sensibilidade orientada ao latino-americanismo e à ideia regional.

Retomar os debates das cinco conferências de faculdades latino-americanas realizadas durante a segunda metade do século passado constitui esforço necessário para o desenvolvimento do projeto "Repensar la Educación en Derecho Internacional en América Latina" (REDIAL), do qual participo com outros colegas latino-americanos. Importante frisar, este estudo busca contribuir diretamente para os questionamentos empreendidos no âmbito do projeto REDIAL. Em outras palavras, para além de mero saudosismo ou de simplesmente celebrar a realização de conferências de advogados realizadas no passado, este trabalho busca oferecer elementos concretos que possam informar as reflexões sobre a conformação de uma perspectiva crítica em Direito Internacional que dialogue com a América Latina de hoje, com os problemas enfrentados em nossa região na contemporaneidade. Nesse contexto, não se faz necessária uma reconstrução histórica e exaustiva das cinco conferências de faculdades de direito latino-americanas. De forma semelhante, também não constitui objeto deste estudo analisar a efetividade das mudanças propostas nesses encontros em faculdades de direito da região. Assim, este artigo não busca apresentar problemas e possíveis soluções em matéria de ensino do direito internacional na América Latina. Como será visto mais adiante, a análise histórica que se propõe está menos orientada à apresentação de soluções ou de uma teoria geral sobre ensino jurídico e mais

teoría social especialmente, un extenso y profundo cambio social, que debía ser llevado a cabo". SIERRA. Derecho, cambio social y los juristas en Chile, cit., 2. 
focada em apresentar subsídios para debates presentes sobre os contornos de uma perspectiva crítica em direito internacional na América Latina atual.

Claro, um exercício de construção de uma abordagem crítica latino-americana em direito internacional na atualidade pode interessar a muitas pessoas em nossa região, não somente aos membros do projeto REDIAL, o que me parece justificar a publicação deste texto. No entanto, o que quero deixar claro é o objetivo "presentista" deste estudo. A retomada de discussões pretéritas sobre ensino jurídico na região possui escopo bastante concreto e atual: contribuir para as reflexões sobre como ensinar, pesquisar, estudar e praticar o Direito Internacional a partir de uma perspectiva que dialogue com os problemas atuais da América Latina.

O argumento se desenvolverá da seguinte forma. A próxima parte do texto apresentará os contornos da análise histórica que se pretende apresentar ao leitor neste estudo. Inspirado pelo trabalho de Anne Orford ¿El passado como derecho o como historia? La relevância del imperialismo para el derecho internacional moderno ${ }^{10}$ e pelas considerações apresentadas por Luis Eslava, Liliana Obregón e René Urueña em seu estudo preliminar publicado em Imperialismo y derecho internacional: historia y legado ${ }^{11}$, será explorado o engajamento entre direito internacional e história que norteia as ideias apresentadas neste trabalho. Em seguida, serão expostas brevemente as principais temáticas discutidas nas conferências em análise, sem qualquer pretensão de uma análise exaustiva, como já mencionado. A parte seguinte procurará discutir a importância de se considerar esses debates pretéritos, explorando com um pouco mais de profundidade a sua importância para os objetivos mais gerais do projeto REDIAL, em especial a busca por uma perspectiva crítica em direito internacional que dialogue com o contexto corrente em nossa região. $\mathrm{O}$ texto se encerra com algumas considerações conclusivas.

\section{DIREITO INTERNACIONAL E HISTÓRIA: CONSIDERAÇÕES SOBRE OS USOS DE TEXTOS DO PASSADO PELO JURISTA INTERNACIONALISTA}

A prática do direito internacional no passado e na contemporaneidade possui impacto substantivo não apenas nas relações entre os tradicionais sujeitos de

10 ORFORD, A. ¿El passado como derecho o como historia? La relevância del imperialismo para el derecho internacional moderno, in ANGHIE, A., KOSKENNIEMI, M., ORFORD, A. Imperialismo y derecho internacional. Estúdio preliminar: Eslava, L., Obregón, L., Urueña, R. Bogotá, Siglo de Hombre Editores, Universidad de los Andes, Pontificia Universidad Javeriana, 2016, 191-227.

11 EslaVa, L., Obregón, L., UrueÑa, R. Imperialismo(s) y derecho(s) internacional(es): ayer y hoy, in ANGHIE, A., Koskenniemi, M., ORFord, A. Imperialismo y derecho internacional. Estúdio preliminar: Eslava, L., Obregón, L., Urueña, R. Bogotá, Siglo de Hombre Editores, Universidad de los Andes, Pontificia Universidad Javeriana, 2016, 11-94. 
direito internacional, os Estados, mas também no plano doméstico e, especialmente, na vida das pessoas. Nesse sentido, autores como Martti Koskenniemi, Anne Orford, Antony Anghie, entre outros, têm relacionado história, teoria e crítica em direito internacional para interrogar as origens europeias e imperialistas desse campo, desafiando suas ambições universalistas e ressaltando as diferentes formas de articulação do direito internacional em diferentes contextos locais e em diferentes momentos da história. Importante sublinhar que as dimensões internacional e local não existem em isolamento uma da outra, mas em interações de implicação mútua e co-constituição. Nesse sentido, não somente a dimensão local é influenciada por práticas internacionais de caráter imperialista, mas o movimento inverso também se verifica, com a influência da dimensão local no plano internacional. Como afirmam Eslava, Obregón e Urueña:

La cara local del imperialismo galvanizó así la consolidación de identidades e intereses nacionales y generó como contrapartida la formalización de la esfera internacional. En la nueva esfera (o nivel) internacional las potencias europeas comenzaron a usar, de manera cada vez más refinada, el derecho internacional para avanzar sus propios intereses nacionales. La relación entre lo nacional e internacional no solo se implementó dentro de Europa, sino que también se convirtió en el horizonte para pensar cómo se podrían conducir las relaciones entre el centro y la periferia más allá del marco imperialista ${ }^{12}$.

É produtivo, assim, explorar a prática atual e pretérita do direito internacional não somente a partir da perspectiva central (europeia), mas também considerando perspectivas periféricas e a produção de juristas internacionalistas de diversos locais do mundo. Em especial, a América Latina possui experiências passadas em matéria de direito internacional bastante ricas e complexas, mas apesar da tradição de renomados juristas internacionalistas latino-americanos, incluindo autores como Andrés Bello, Carlos Calvo, Alejandro Álvarez, Rui Barbosa ${ }^{13}$,

12 Ibid., 27-28.

13 A esse respeito. Ver ObRegón, L. Latin American International Law, in Routledge Handbook of International Law, David Armstrong (ed.) London-New York, Routledge, 2009, 154-164; OBREGón, L. ¿Para qué un derecho internacional latinoamericano? In URUEÑa, R. (comp.). Derecho internacional: poder y límites del derecho en la sociedad global. Bogotá, Universidad de Los Andes, 2015, 27-60; BeCKer LorCA, A. Mestizo International Law: A Global Intellectual History 1842-1933, Cambridge, Cambridge University Press, 2014; BECKER LORCA, A. International Law in Latin America or Latin American International Law? Rise, Fall, and Retrieval of a Tradition of Legal Thinking and Political Imagination, Harvard International Law Journal. V. 47. N. 1, 2006, 283-305; EsQuirol, J. L. Alejandro Álvarez's Latin American Law: A Question of Identity, Leiden Journal of International Law. V. 19. N. 4, 2006, 931-956; EsQuirol, J. L. Latin America, in Fassbender, B., Peters, A. (eds.). The Oxford Handbook of the History of International Law. Oxford, Oxford University, 2012, 553-585; CarvalHo Veçoso, F. F.; Ribeiro Roriz, J. H. y SANCTIS DE BRITo, A. "Seremos julgados": revisitando o debate entre Álvarez e Sá Vianna sobre a regionalização do direito internacional na América Latina, in Liliana Jubilut (org.). Direito Internacional Atual. Rio de Janeiro, Elsevier, 2014, 287-315. 
Epitácio Pessoa ${ }^{14}$, entre outros, o ensino do direito internacional na região tem se caracterizado por um acentuado dogmatismo, baseado na reprodução de abordagens eurocêntricas e estadunidenses ${ }^{15}$. Adotado de forma acrítica, o direito internacional parece ser visto como algo politicamente neutro ${ }^{16}$, em que a América Latina poderia somente contribuir com teorias e doutrinas para o progressivo desenvolvimento do campo. Assim, perspectivas que articulam teoria, história e crítica em direito internacional atualmente têm alcance restrito na região, mesmo com a forte presença da experiência colonial entre nós ${ }^{17}$.

Neste contexto, o projeto REDIAL possui como objetivo principal criar uma plataforma acadêmica de trabalho colaborativo para juristas internacionalistas latino-americanos, fomentando o compartilhamento de práticas de ensino e de pesquisa que dialoguem com uma perspectiva crítica direcionada aos problemas concretos enfrentados atualmente na região ${ }^{18}$.

No entanto, muitos questionamentos desafiam a ideia de uma perspectiva crítica latino-americana em direito internacional atualmente. No âmbito do projeto REDIAL, não há uma definição pronta e acabada sobre qual seria uma abordagem crítica própria ao contexto corrente em nossa região. Sensibilidades latino-americanas já foram articuladas no passado em relação ao direito internacional e essas sensibilidades têm também se transformado na medida em que a ideia sobre América Latina circula em diferentes momentos no tempo e em diferentes espaços. Assim, apenas para ilustrar, a sensibilidade latino-americana articulada por Alejandro Álvarez na virada do século xx não é a mesma sensibilidade latino-americana articulada pelos delegados participantes nas conferências de faculdades de direito entre os anos 1959 e 1974. Da mesma forma, o momento atual e os diversos contextos locais em que

14 Franca Filho, M. T.; Mialhe, J. L.; Job, U. Da Silveira (orgs.). Epitácio Pessoa e a codificação do direito internacional. Porto Alegre, Sergio Antonio Fabris Editor, 2013.

15 Vale ressaltar que esse é um aspecto não somente do ensino do direito internacional, mas também do ensino de outros campos do direito, como argumenta MonToYa, J. The Current State of Legal Education Reform in Latin America: A Critical Appraisal, Journal of Legal Education. V. 59. N. 4, 2010, 545-566.

16 Sobre projetos (políticos) relacionados ao direito internacional. Ver CRAWFORD, J., Koskenniemi, M. Introduction. In Crawford, J., Koskenniemi, M. (eds.). The Cambridge Companion to International Law, Cambridge, Cambridge University Press, 2012, p. 1-21.

17 "A pesar de que la cuestión imperial hace parte del pasado y presente de América Latina, las nuevas aproximaciones [estudios críticos del derecho internacional y aproximaciones desde el Tercer Mundo al derecho internacional] se conocen poco en la región; quizás por su falta de traducción a la lengua castellana, o por un arraigo académico histórico al derecho internacional 'clásico' que presenta una visión de un futuro mejor, un progreso linear de la disciplina y le da una mínima importancia al pasado". EsLAVA, OBREGón e URUEÑa, R. Imperialismo(s) y derecho(s) internacional(es): ayer y hoy, cit., 18.

18 Sobre o projeto Redial. Ver Acosta Alvarado, P. A. Enseñar e investigar derecho internacional en Latinoamérica. Un ejercicio de catarsis. Serie Documentos de Trabajo n. ${ }^{\circ}$ 46, Departamento de Derecho Constitucional, Facultad de Derecho, Universidad Externado de Colombia, 1-17, in: http://www.icrp.uexternado.edu.co/. 
se articula o direito internacional em nossa região oferecem complexidades e desafios diversos do quanto verificado na segunda metade do século $\mathrm{xx}^{19}$.

Revisitar os debates realizados na segunda metade do século passado sobre pedagogia jurídica, desenvolvimento e modernização constitui-se em empreitada útil para enfrentar os questionamentos a respeito de uma abordagem crítica em direito internacional para a América Latina de hoje. Trata-se de contexto recente, porém pouco explorado por juristas internacionalistas de nossa região. Sem pretender um mero transplante de ideias, retomar discussões do passado nos ajuda a iluminar desafios presentes e esse o objetivo maior deste trabalho.

O engajamento entre história e direito internacional que orienta os argumentos expostos neste artigo dialoga com os estudos de Anne Orford sobre o papel do passado em debates jurídicos contemporâneos. Especificamente, como explorado em ¿El passado como derecho o como historia? La relevância del imperialismo para el derecho internacional moderno ${ }^{20}$, a autora apresenta sua análise a respeito da crítica formulada por certo grupo de historiadores aos estudos históricos realizados atualmente por juristas internacionalistas. Segundos historiadores ligados à vertente contextualista no campo da histórica intelectual, juristas internacionalistas fazem uso anacrônico de textos históricos, buscando abordar debates presentes em direito internacional por meio do uso de textos do passado sem considerar propriamente o contexto histórico em que tais materiais foram escritos. Para essa vertente contextualista, textos do passado serão compreendidos adequadamente se interpretados em conformidade com o contexto em que foram produzidos, ou seja, de acordo com o momento pretérito em que tais materiais foram elaborados. No entender desse grupo de historiadores, preocupações "presentistas" ao analisar textos do passado seriam inadequadas justamente por introduzir questões alheias ao contexto da época.

19 Recente publicação editada por César Rodríguez-Garavito retoma as reflexões sobre o papel transformador do direito na sociedade. De acordo com o autor, seguimos repetindo análises pretéritas sobre o direito na América Latina, já que "many of the old assumptions about Latin American legal institutions and culture continue to creep into contemporary scholarship and reform projects". RodríGUEZ-GARAVITO, C. Remapping law and society in Latin America. Visions and topics for a new legal cartography. In RODRíGUEZ-GARAVITO, C. (ed.). Law and Society in Latin America. A new map. New York, Routledge, 2015,2. Tal repetição acontece, segundo o autor, por conta de uma persistente influência do paradigma do direito e desenvolvimento, especialmente a primeira onda de estudos realizados nos anos sessenta. Assim, "such assumptions tend to depict Latin American legal fields as marked by large gaps between norms and practice, exacerbated legal pluralism, clientelistic legal cultures, and authoritarianism”. RodríGUEZ-GARAVITO. Remapping law and society in Latin America, cit., 2. Não será possível explorar essas considerações de Rodríguez-Garavito sobre o contexto atual do papel do direito na América Latina neste trabalho, mas a menção a essa recente publicação demonstra que a sensibilidade latino-americana continua se transformando em novos momentos históricos e em novos espaços.

20 Supra nota 10. 
Anne Orford defende entendimento diverso, baseado nas diferenças na forma como historiadores e juristas internacionalistas utilizam textos passados. Apesar de ambos olharem para materiais elaborados no passado, o uso de textos históricos em direito internacional constituiria um exercício diverso do quanto empreendido por historiadores, já que conceitos jurídicos se movem no tempo e no espaço, não sendo possível traçar um limite claro e definitivo entre o passado e o presente. Segundo Orford, ideias, conceitos e princípios jurídicos se transformam diante de mudanças verificadas no mundo. Análises anacrônicas seriam, assim, próprias ao exercício de análise do jurista internacionalista ao trabalhar com textos do passado. A análise histórica em direito internacional permitiria uma melhor compreensão de práticas presentes justamente por dar conta das diversas transformações verificadas em ideias, conceitos e princípios jurídicos em diferentes momentos no tempo e no espaço ${ }^{21}$.

Essas considerações sobre a abordagem de Anne Orford sobre estudos históricos em direito internacional são relevantes pois permitem compreender o tipo de análise que se pretende realizar neste artigo sobre as conferências latino-americanas de faculdades de direito realizadas durante a segunda metade do século xx. Não se busca empreender uma reconstrução histórica exaustiva do contexto em que tais conferências foram realizadas. Retomar os debates realizados nesses encontros é importante devido à uma necessidade verificada no presente: embasar reflexões inovadoras sobre o ensino do direito internacional na América Latina na atualidade. Como será visto na próxima seção do texto, reformas pedagógicas foram propostas nas faculdades de direito latino-americanas a partir de uma sensibilidade regional, revelando-se a necessidade de atrelar projetos políticos a essas iniciativas de reforma. Não se trata aqui de afirmar que devemos simplesmente repetir as medidas propostas no passado, mas compreender como os debates sobre reforma pedagógica foram influenciados por determinadas visões políticas relacionadas ao desenvolvimento e modernização da região. Reflexões inovadoras e atuais sobre a prática, o ensino e a pesquisa do direito internacional a partir de uma perspectiva latino-americana demandam uma perspectiva política mais ampla sobre os problemas que afligem nossa região na contemporaneidade. Não defendo o mero transplante dos debates ligados à corrente do direito e desenvolvimento para o tempo presente, mas sim a necessidade de perceber como uma compreensão sofisticada dos problemas regionais é fundamental para embasar a conformação de uma perspectiva crítica em direito internacional

21 "Para Orford, el punto clave para tener en cuenta es que a diferencia de la disciplina de la historia, en el derecho (como en la política) el pasado es fuente de obligaciones. Esto implica que toda mirada al pasado desde el derecho implica preguntas acerca de cómo y en qué nivel el pasado habla o de da forma al presente". EsLAVA, OBReGón e Urueña. Imperialismo(s) y derecho(s) internacional(es): ayer y hoy, cit., 92. 
a partir da América Latina. Neste sentido, esse artigo busca redescrever ${ }^{22}$ os debates realizados nas cinco conferências latino-americanas como esforço de análise histórica necessário para as reflexões atuais sobre a prática do direito internacional em nossa região.

\section{CONFERÊNCIAS DE FACULDADES DE DIREITO \\ LATINO-AMERICANAS: BREVES NOTAS}

Questionar sobre, comparar e descrever o ensino do direito na América Latina não constitui esforço único ou isolado, tampouco esforço recente. Apenas para ilustrar, em obra publicada em 1909, Manuel Arbelaiz, professor catedrático de direito internacional da Universidade de Montevidéu, apresentou seu plano de ensino ou "programa analítico", listando e detalhando os temas tratados em seu curso em duas grandes partes, "Estado de Paz" e "Estado de Guerra" ${ }^{23}$. O autor também apresentou considerações de caráter pedagógico sobre o ensino do direito internacional, analisando as estratégias didáticas da aula expositiva, diálogo socrático e debates em sala ${ }^{24}$, além de questionamentos sobre métodos de avaliação ${ }^{25}$ e sobre a necessidade de adoção de manuais para o estudo do direito internacional ${ }^{26}$. Arbelaiz disserta, de forma interessante, sobre a relação benéfica entre história e direito internacional para o aprendizado desse último ${ }^{27}$.

Em estudo mais recente, publicado em 1950 pelo Journal of Legal Education, H. Claude Horack analisou trinta e sete faculdades de direito oriundas de dezesseis diferentes países latino-americanos ${ }^{28}$. Esse estudo foi realizado

22 OrFord, A. In praise of description. Leiden Journal of International Law. V. 25. N. 3 , 2012, 609-625.

23 Arbelaiz, M. La enseñanza del derecho internacional público. Montevideo: Escuela de Artes y Oficios, 1909.

24 Ibid., 94-98.

25 Ibid., 98-99.

26 Ibid., 104-108.

27 "La historia así entendida sin misión preceptista ni censora, nos dirá que hay lógica en una serie de acontecimientos que nos parecen chocar entre sí, que hay armonía donde la mirada superficial solo ve desconcierto y que en ocasiones los actos de un país que mirados del punto de vista general son irritantes, equivalen interpretados según el momento, á la expresión de una conducta obligatoria [...] En ninguna rama del derecho hay ocasiones de aplicar la historia con más frecuencia ni más utilidad que en la esfera del Derecho Internacional! [...] Ella [la historia] nos demostrará que la doctrina de tal ó cual país en ciertas épocas y sobre ciertos hechos, no debemos juzgarlas según cánones inmutables y que lo que es condenable según criterios radicales, resulta admisible como consecuencia obligada de determinadas circunstancias". Ibid., 100-101.

28 Horack, H. C. Legal Education in the Latin-American Republics. Journal of Legal Education. V. 2. N. x, 1950, 287-297. Horack foi professor da Duke Law School e sua pesquisa contou com o apoio da Inter-American Bar Association, além de financiamento do Departamento de Estado dos Estados Unidos da América. $\mathrm{O}$ autor visitou trinta e sete faculdades de direito nos seguintes países: Equador, Peru, Bolívia, Chile, Argentina, Uruguai, Paraguai, Brasil. Venezuela, Colômbia, Guatemala, Honduras, México, Haiti, República Dominicana e Cuba. Ibid., 287. 
com o propósito específico de justificar a perspectiva da Inter-American Bar Association sobre os aspectos positivos advindos do intercâmbio entre alunos e professores de direito entre países do continente americano ${ }^{29}$. Mesmo considerando o viés estadunidense desse estudo, Horack foi capaz de perceber questões muitas vezes utilizadas para descrever o ensino jurídico latino-americano:

Teaching is largely by the lecture method except in seminars and practice court work. [...] All the schools have been influenced by the formal lecture methods of the continental law schools, particularly those of Spain, France, and Italy where until recent years many students and professors went for special or post-graduate study. Thus it is not unusual to find a lecturer who asks no questions of the students and permits no questions by them, but delivers a formal lecture which is mimeographed or printed and given out to the students. When this is not done a few students take shorthand notes of the lecture which are then transcribed and given out to their fellows. In many schools this practice is encouraged ${ }^{30}$.

No Brasil, críticas ao método de aula expositiva ou magistral e à produção de conhecimento descritivo sobre normas e instituições jurídicas foram articuladas por San Tiago Dantas nos anos cinquenta. San Tiago Dantas era então professor da Faculdade Nacional de Direito, à época Universidade do Brasil (atualmente Universidade Federal do Rio de Janeiro). Em sua aula inaugural realizada em 1955 e intitulada "A educação jurídica e a crise brasileira" 31 , Dantas apresentou novas diretrizes para o estudo do direito no Brasil. Ele defendeu a adoção do método do caso como estratégia de ensino mais adequada, oposta ao tradicional conhecimento descritivo e sistemático de instituições e normas jurídicas. San Tiago Dantas também defendeu o ensino jurídico interdisciplinar como condição importante para a readequação da prática do direito ao contexto moderno ${ }^{32}$.

29 American Bar Association. 1949 Proceedings of Section of International and Comparative Law. Part V, General Committee Reports; 5. Horack Survey of Latin American Law Schools, 186.

30 Horack. Legal Education, cit., 288.

31 Sobre a história da Faculdade Nacional de Direito e sobre a aula inaugural de Dantas. Veja a página eletrônica da Faculdade de Direito da Universidade Federal do Rio de Janeiro: http://www.direito.ufrj.br/index.php/historico

32 "O ponto de onde, a meu ver, devemos partir, nesse exame do ensino que hoje praticamos, é a definição do próprio objetivo da educação jurídica. Quem percorre os programas de ensino das nossas escolas, e sobretudo quem ouve as aulas que nelas se proferem, sob a forma elegante e indiferente da velha aula-douta coimbrã. Vê que o objetivo atual do ensino jurídico é proporcionar aos estudantes o conhecimento descritivo e sistemático das instituições e normas jurídicas. Poderíamos dizer que o curso jurídico é, sem exagero, um curso dos institutos jurídicos, apresentados sob a forma expositiva de tratado teórico-prático". DANTAS, S. T. Aula inaugural dos cursos da Faculdade Nacional de Direito, 1955. In Ensino Jurídico. Encontros da UnB, Brasília, UnB, 1978/79, 45 . 
Os anos cinquenta e sessenta também foram marcados por estudos patrocinados pela UNESCO para a compreensão do ensino universitário em vários campos do saber, com análises focadas em certos grupos de países. O relatório sobre o ensino do direito, elaborado por Charles Eisenmann, foi publicado em 1954 e posteriormente em 1972 com a inclusão de análises de novo grupo de países ${ }^{33}$. Em 1967, foi publicado relatório sobre ensino do direito internacional elaborado por René Jean Dupuy e Gyr“gy Haraszti ${ }^{34}$. Na assembléia final da Primeira Conferência de Faculdades de Direito Latino-Americanas, o relator geral do encontro afirmou expressamente serem inadequados para a América Latina os achados compilados no relatório da UNESCO sobre ensino do direito ${ }^{35}$.

Como já mencionado, entre 1959 and 1974, cinco conferências internacionais reuniram delegados de faculdades de direito latino-americanas para trocar experiências relacionadas ao ensino, à pesquisa e à extensão universitária, no contexto já referido de reflexão sobre a modernização dessas faculdades, isto é, com foco particular no papel do direito para o desenvolvimento dos países da região ${ }^{36}$. A primeira dessas Conferencias de Facultades y Escuelas Latinoamericanas de Derecho foi realizada na Cidade do México, em 1959. Após, as conferências se realizaram em Lima (1961), Santiago de Chile

33 Fix-Zamudio, H. Algunas reflexiones sobre la enseñanza del derecho en México y Latinoamérica, cit., 79. Para íntegra do relatório da UNESCO sobre ensino jurídico publicado em 1954, http://unesdoc.unesco.org/images/0000/000028/002860eo.pdf

34 Disponível em: http://www.unesco.org/ulis/cgi-bin/ulis.pl?catno=4859\&set=00589B 07AD_3_82\&gp=1\&lin=1\&ll=1

35 "De aquí que rechacemos como impertinentes a nuestro mundo jurídico los juicios vertidos por los profesores John N. Hazard (Universidad de Columbia, Nueva York), y Charles Eisenmann (Universidad de París), prologuista y autor, respectivamente, del informe que la UNESA destinó al Derecho (1954) en su Colección 'Las Ciencias Sociales en la Enseñanza Superior', en el sentido -afirman-de que los maestros del derecho participan hoy cada vez más en una creciente ola crítica contra los métodos y fines de sus enseñanzas, sin que entre ellos, individual o colectivamente, apunte tan siquiera la conciencia de que tal estado de cosas es superable y aún está en vías de superación. El organismo internacional aludido se considera el llamado, el primero, para formarla o impulsarla.

"Con idéntico apoyo en los documentos reunidos en esta Conferencia, no podemos aceptar como ajustado a la realidad de la enseñanza jurídica latinoamericana el aserto, repetido sin mayor examen en el decir usual y recepcionado, a veces en piezas oficiales, en orden a que ella aún se mantiene adscrita al método exegético y, por ende, al predominio irrestricto de las fuentes legisladas. Tal problemática pudo tener vigencia a fines del siglo pasado y en los dos primeros decenios del actual, pero hoy la dificultad técnica en la casi totalidad de nuestros países y universidades es otra: radica en que el método sistemático, auto calificado de 'científico', que pasó a reemplazar al 'exegético', tiende a perpetuarse sin reforma ni progreso; vale decir que nuestra tarea es evitar el riesgo que así como los códigos heredaron durante el siglo XIX el carácter divino de los reyes, las lecciones magisteriales pretendan ser las únicas sucesoras de las fuentes legisladas en el respeto y el saber de los jóvenes juristas". Primera Conferencia de Facultades/Escuelas Latinoamericanas de Derecho (Ciencias Jurídicas y Sociales). Informes, cit., 444 .

36 Supra nota 8. 
(1963), Montevidéu (1965) e a última em Cordoba em 1974. O contexto de estabelecimento de regimes autoritários em diversos países latino-americanos em diferentes momentos a partir dos anos 60 teve impacto substantivo na implementação das reformas aprovadas nesses encontros regionais. Universidades públicas sofreram intervenção direta dos regimes militares, o que acabou prejudicando a continuidade desse processo de discussão regional sobre a implementação de reformas universitárias estruturais ${ }^{37}$.

As conferências trataram de uma gama ampla de questões ${ }^{38}$. Entre elas, foram apresentados e discutidos relatórios nacionais descrevendo o status do ensino jurídico em várias faculdades de direito da América Latina, com a compilação de planos de estudo de diversas instituições; teses apresentadas por delegados sobre os temas discutidos nas conferências, incluindo debates sobre a missão, as finalidades e as funções das faculdades de direito na região; métodos de ensino ou pedagogía jurídico-social (com fortes críticas tanto sobre o método de aula magistral, tal como descrito por Horack acima, quanto sobre a desconexão entre as faculdades de direito e a realidade social da América Latina na segunda metade do século xx); métodos de avaliação dos alunos; o estabelecimento de relações entre faculdades da região; além de um chamado por uma abordagem interdisciplinar para o estudo do direito ${ }^{39}$, incluindo história, sociologia, filosofia e política. Organizei os temas gerais das cinco conferências na tabela que segue abaixo.

37 Ilustrativamente, sobre o caso do Chile. Veja SiERRA. Derecho, cambio social y los juristas en Chile, cit. No Brasil, a Universidade de Brasília (UnB) criada no início dos anos 60 também sofreu intervenção militar com o golpe de 1964. Após a implementação de um projeto inovador que envolveu o planejamento de uma nova estrutura para a universidade pública brasileira, com o entrelaçamento das diversas formas de saber e a formação de profissionais comprometidos com a transformação do Brasil, a UnB sofreu intervenção direta dos militares, o que também envolveu a saída em massa do corpo docente reunido para colocar em prática essa ambiciosa empreitada liderada por Darcy Ribeiro. RibeIRo. Darcy Ribeiro (depoimento, 1978), cit.

38 Conferencias de Facultades Latinoamericanas de Derecho (Ciencias Jurídicas y Sociales). Anales de la Facultad de Derecho, cuarta época. V. 4. N. 4, 1964-1965; Primera Conferencia de Facultades/Escuelas Latinoamericanas de Derecho (Ciencias Jurídicas y Sociales). Informes, cit.; Tercera Conferencia de Facultades (Escuelas) de Derecho (Ciencias Jurídicas, Políticas y Sociales) Latinoamericanas, cit.; Ovalle Favela, J., Bibliografía. Enseñanza del Derecho y Sociedad en Latinoamérica. V Conferencia de Facultades y Escuelas de Derecho de América Latina. Boletín Mexicano de Derecho Comparado. V. 10. N. 28-29, 1977, 221-228.

39 Pérez-Perdomo, R. Desafíos de la educación jurídica latinoamericana en tiempos de globalización. El Otro Derecho. N. 38, 2009, 16. 
TABELA 1

TEMAS GERAIS CONFERÊNCIAS

\begin{tabular}{|c|c|c|c|c|}
\hline $\begin{array}{l}\text { 1a Conferência } \\
\text { México } 1959\end{array}$ & $\begin{array}{l}\text { 2a Conferência } \\
\text { Lima } 1961\end{array}$ & $\begin{array}{l}\text { 3a Conferência } \\
\text { Chile } 1963\end{array}$ & $\begin{array}{c}\text { 4a Conferência } \\
\text { Montevidéu } \\
1965\end{array}$ & $\begin{array}{c}\text { 5a Conferência } \\
\text { Córdoba } 1974\end{array}$ \\
\hline $\begin{array}{c}\text { Síntese histórica } \\
\text { do ensino do } \\
\text { direito }\end{array}$ & $\begin{array}{c}\text { Ensino do Direito } \\
\text { e Ciências Sociais } \\
\text { em diversos } \\
\text { níveis }\end{array}$ & $\begin{array}{c}\text { Relações entre } \\
\text { faculdades de } \\
\text { direito }\end{array}$ & $\begin{array}{c}\text { (Relações entre } \\
\text { faculdades de } \\
\text { direito) }\end{array}$ & $\begin{array}{l}\text { Docências nas } \\
\text { faculdades de } \\
\text { Direito }\end{array}$ \\
\hline $\begin{array}{l}\text { Estado atual do } \\
\text { ensino do direito }\end{array}$ & $\begin{array}{l}\text { Matérias básicas } \\
\text { dos planos } \\
\text { de ensino das } \\
\text { faculdades }\end{array}$ & $\begin{array}{c}\text { Pedagogia } \\
\text { jurídicosocial }\end{array}$ & Planos de Estudo & $\begin{array}{l}\text { Coordenação } \\
\text { interdisciplinar }\end{array}$ \\
\hline \multirow[t]{3}{*}{$\begin{array}{c}\text { Documentos } \\
\text { e informações } \\
\text { complementares }\end{array}$} & $\begin{array}{c}\text { Seminários } \\
\text { de Direito e } \\
\text { Ciências Sociais } \\
\text { (aprendizagem } \\
\text { ativa) }\end{array}$ & $\begin{array}{c}\text { Missão } \\
\text { faculdades de } \\
\text { Direito }\end{array}$ & $\begin{array}{l}\text { Carreira docente } \\
\text { e do pesquisador }\end{array}$ & $\begin{array}{c}\text { O jurista } \\
\text { e o Estado } \\
\text { contemporâneo }\end{array}$ \\
\hline & $\begin{array}{l}\text { Ensino de prática } \\
\text { jurídica }\end{array}$ & & $\begin{array}{l}\text { Formação cultural } \\
\text { e assistência } \\
\text { pedagógico-social } \\
\text { do estudante }\end{array}$ & \\
\hline & $\begin{array}{c}\text { Criação de } \\
\text { Institutos Latino- } \\
\text { Americanos }\end{array}$ & & $\begin{array}{c}\text { (Missão } \\
\text { faculdades de } \\
\text { direito ante } \\
\text { problemática das } \\
\text { comunidades) }\end{array}$ & \\
\hline
\end{tabular}

Fonte: Elaboração própria.

De forma geral, em todas as conferências houve a realização de palestras relacionadas aos temas que integraram o programa dos encontros, as quais foram organizadas pelos respectivos Comitês Organizadores. A faculdade sede da conferência era responsável pela propositura do temário do encontro, o qual era disponibilizado às demais faculdades antes da realização do evento, com a possibilidade de propositura de novos temas ao Comitê Organizador. Da mesma forma, era franqueado às faculdades participantes a apresentação de trabalhos, os quais deveriam ser submetidos aos organizadores do encontro com antecedência e segundo regras estabelecidas nos regulamentos internos de cada conferência. Os trabalhos enviados eram disponibilizados aos participantes e posteriormente publicados nos anais das conferências, cuja publicação ficava a cargo da faculdade sede. Finalmente. Vale mencionar que do ponto de vista da organização interna, foram criadas comissões de trabalho para o discussão dos temas dos programas das conferências e dos respectivos trabalhos apresentados pelas delegações de faculdades. As assembleias gerais das conferências deliberavam sobre o quanto proposto pelas comissões, com votações organizadas por maioria simples - apenas 
um voto por delegação de faculdade de direito, sendo que observadores não possuíam direito à voto.

A primeira conferência de faculdades de direito latino-americanas buscou possibilitar um mapeamento histórico e atual do ensino do direito na região, etapa vista como necessária para a propositura de reformas mais profundas. Assim, as faculdades participantes apresentaram monografías com relatos históricos sobre as respectivas instituições, além de dados atuais sobre sua organização interna e funcionamento, o que permitiu a preparação de documentos informativos sobre considerável conjunto de instituições a partir dos trabalhos apresentados. O plano das monografías a serem apresentadas durante a primeira conferência foi definido previamente pelo Comitê Organizador mexicano, de forma que todas as faculdades participantes tiveram um modelo comum para apresentação das respectivas narrativas históricas e contexto atual. Buscou-se assim mapear os antecedentes históricos das faculdades de direito, incluindo marcos importantes como reformas estruturais passadas, além de comentários críticos. Para um mapeamento do estado atual do ensino do direito na América Latina, as faculdades apresentaram seus objetivos de ensino e pesquisa, as funções que cumprem respectivas faculdades, além de sua organização e metodologia de ensino e pesquisa da instituição (incluindo planos de estudo, com informações detalhadas sobre distribuição das matérias e carga horária, títulos acadêmicos e profissionais concedidos pela instituição; descrições da metodologia de ensino e das estratégias de avaliação; requisitos para ingresso dos alunos; possibilidade de revalidação de estudos realizados em outras instituições; além da organização interna da faculdade). Esse mapeamento do estado atual do ensino do direito em cada faculdade também foi acompanhado de comentários críticos. Finalmente, o Comitê Organizador da primeira conferência sistematizou documentos apresentados pelas faculdades e as informações constantes nesses materiais, compilando planos de estudo, dados estatísticos sobre alunos inscritos no ano de 1958, lista de professores, lista de manuais jurídicos utilizados, lista de periódicos das faculdades, entre outros ${ }^{40}$.

Um dos resultados relevantes da primeira conferência de faculdades de direito latino-americanas realizada no México foi a elaboração de uma $D e$ claración de Principios sobre la Enseñanza del Derecho (Ciencias Jurídicas y Sociales) en América Latina, a partir de vários anteprojetos de declaração apresentados por professores de faculdades de direito latino-americana ${ }^{41}$. Um esboço final da declaração foi apresentada no México ${ }^{42}$ e discutida nos encontros seguintes.

40 Primera Conferencia de Facultades/Escuelas Latinoamericanas de Derecho (Ciencias Jurídicas y Sociales). Informes, cit., 19-22.

41 Ibid., 269-378.

42 Ibid., 447-455. 
A apresentação de uma declaração final de princípios é relevante pois demonstra a profundidade dos questionamentos articulados pelas delegações de faculdades de direito já nesse primeiro encontro. Os dois primeiros tópicos dessa declaração apresentam os objetivos e as funções das faculdades de direito latino-americanas, o que mostra o intuito maior de reforma profunda dessas instituições, intuito motivado pelo já mencionado contexto de debates sobre o papel da universidade no desenvolvimento e modernização da região. Assim, afirmou-se no México em 1959:

1. Compete, en general, a las Facultades de Derecho de América Latina, la investigación, enseñanza y difusión de los sistemas jurídicos que:

a) Contribuyen a la formación de una conciencia colectiva basada en el reconocimiento de la dignidad de la persona humana y en los ideales de justicia, de democracia, de paz y libertad;

b) Realicen la justicia social que permita incorporar las masas populares a un régimen de bienestar general;

c) Fomenten, con base en la unidad espiritual de la América Latina, un pensamiento filosófico jurídico propio;

d) Formen una conciencia cívica tendiente al cumplimiento de los deberes ciudadanos y de servicios social;

e) Estimulen la custodia, el progreso y la extensión de la cultura jurídica nacional, latinoamericana y universal, $y$

f) Pugnen por el buen funcionamiento de la administración de la justicia y por el respeto a la norma jurídica positiva ${ }^{43}$.

A segunda conferência de faculdades de direito latino-americanas foi realizada em Lima em 1961 com foco em questões pedagógicas. Assim, discutiu-se o ensino do direito em nível de graduação e as particularidades do chamado ensino "pré-jurídico". Os planos de ensino de matérias básicas das faculdades de direito foram coletados e debatidos no encontro, além de questões relacionadas à aprendizagem ativa, com discussões sobre a realização de seminários em sala de aula. O ensino de prática jurídica também foi objeto de deliberação, com discussões focadas nas técnicas do manejo de fontes, clínica jurídica e atividades práticas nas faculdades de direito. Finalmente, foi debatida a criação de institutos de pesquisa latino-americanos, um instituto voltado à pesquisa do direito comparado e outro focado em Ciências Sociais e Políticas ${ }^{44}$.

A terceira conferência realizada no Chile em 1963 retomou algumas discussões pedagógicas, além de abordar o estabelecimento de relações institucionais entre faculdades de direito (vistas como absolutamente neces-

43 Ibid., 447.

44 Conferencias de Facultades Latinoamericanas de Derecho (Ciencias Jurídicas y Sociales). Anales de la Facultad de Derecho, cit. 
sárias) e revisitou os debates sobre a missão dessas faculdades na América Latina. As questões pedagógicas foram discutidas sob a expressão pedagogía jurídico-social e trataram dos cursos nas faculdades que não teriam exames finais, questões de avaliação, utilização de materiais audiovisuais para uma pedagogia ativa, carreira docente, ensino de prática jurídica, extensão universitária, além do fomento para a criação de academias de pedagogia voltadas para o ensino do direito. Por seu turno, as relações entre faculdades foram pensadas a partir de temas específicos, incluindo a elaboração de estatuto das conferências, estatutos de institutos de pesquisa latino-americanos, diretrizes para organizar o intercâmbio de estudantes e professores, diretrizes para a edição de obras jurídicas na região e diretrizes para a permuta de bibliografia e documentos. Por fim, a missão das faculdades de direito foi rearticulada para possibilitar a criação de um pensamento comum na região. Voltado à preservação de direitos humanos (com discussões para a criação de um "Estatuto Jurídico do Homem Americano"), preservação constitucional da paz, responsabilidade interna dos Estados, democracia representativa, reformas estruturais, problemática institucional do desenvolvimento, problemática jurídico-social do livre-comércio e técnica legislativa ${ }^{45}$. Importante mencionar que os debates realizados em torno da ideia do "homem americano" tiveram como foco a concretização de direitos econômicos e sociais ${ }^{46}$. No entanto, apesar da apresentação de um projeto de resolução para o "Estatuto Jurídico do Homem Americano", não houve deliberação final sobre essa temática, sendo decidido que a próxima conferência deveria retomar essas discussões ${ }^{47}$. Os debates e questionamentos da conferência chilena deixam ainda mais clara a conexão entre a realização das conferências e o contexto de debates sobre direito, modernização e desenvolvimento, com envolvimento dos advogados da região nessas discussões mais amplas. Os anos sessenta foram anos de efervescência intelectual no Chile ${ }^{48}$, o que certamente contribuiu para a elaboração de temática aprofundada pelo Comitê Organizador chileno sobre a missão das faculdades de direito na América Latina.

Em Montevidéu em 1965 foi realizada a quarta conferência de faculdades de direito latino-americanas, com a retomada de alguns temas debatidos no Chile (uma sessão prévia sobre as relações entre faculdades, com o objetivo de receber mais documentos e informações para as questões debatidas no Chile; e uma sessão final sobre a missão específica da faculdade de direito ante a problemática da comunidade, isto é, o papel das faculdades de direito para a promoção social e cultural da comunidade em que se inserem, com

45 Tercera Conferencia de Facultades (Escuelas) de Derecho (Ciencias Jurídicas, Políticas y Sociales) Latinoamericanas, cit., 11-12.

46 Ibid., 501.

47 Ibid., 505.

48 SIERRA. Derecho, cambio social y los juristas en Chile, cit. 
a criação de centros comunitários nos bairros das cidades, formação cívica, assistência jurídica gratuita etc.). Três temas centralizaram os debates em Montevidéu: discussão sobre planos de estudo das matérias obrigatórias e eletivas do curso de direito, além da definição uniforme quanto à duração geral de curso (período de cinco anos); carreiras do professor e do pesquisador e formação cultural e assistência pedagógico-social dos estudantes das faculdades de direito ${ }^{49}$.

Finalmente, em Córdoba em 1974 foi realizada a última das conferências de faculdades de direito latino-americanas nesse contexto de debates sobre direito, modernização e desenvolvimento. Três foram os temas centrais discutidos nesse encontro, quais sejam, a docência nas faculdades de direito, a coordenação interdisciplinar e o papel do jurista no Estado contemporâneo ${ }^{50}$. Em Córdoba já se percebem as transformações políticas sentidas na região pela ocorrência de golpes de Estado. Falas mais tradicionais sobre o papel do jurista na sociedade já são reproduzidas por delegados chilenos, por exemplo, sem menção ao papel transformador da faculdade de direito pelo desenvolvimento da região $0^{51}$.

\section{A IDEIA REGIONAL: OPORTUNIDADE DE DESENVOLVIMENTO DE ESTUDOS CRÍTICOS EM DIREITO INTERNACIONAL NA AMÉRICA LATINA HOJE?}

Revisitar os temas debatidos nas cinco conferências de faculdades de direito latino-americanas, tal como descrito na seção anterior, permite articular considerações importantes para as reflexões mais amplas sobre a possibilidade e os contornos de uma abordagem crítica em direito internacional sintonizada com as complexidades correntes da nossa região.

Em primeiro lugar, os esforços de debate entre delegações de faculdades de direito estiveram ligados a tentativas aprofundadas de reforma, não somente do ponto de vista pedagógico, mas com a declaração de uma nova missão e de novas funções para as faculdades de direito latino-americanas. De forma mais específica, as transformações pedagógicas foram propostas com um propósito claro, como etapa necessária para a transformação da organização interna da faculdade direito, para que essas instituições tivessem condições de propiciar ensino e pesquisa que dialogassem com projetos de transformação social da época. Essa nova missão incluiu, como visto acima, que faculdades de direito

49 Conferencias de Facultades Latinoamericanas de Derecho (Ciencias Jurídicas y Sociales). Anales de la Facultad de Derecho Cuarta Época, cit.

50 Ovalle Favela. Bibliografía. Enseñanza del Derecho y Sociedad en Latinoamérica, cit.

51 "Para el professor chileno, el papel del jurista se reduce a ser un simple operador del sistema jurídico vigente en un país determinado: su papel 'es hacer operar este sistema y darle eficacia para haver operables sus normas, de hacer entrar en juego la suposición de la coherencia de sus normas, de la ausencia de choques entre ellas"”. Ibid., 228. 
"Realicen la justicia social que permita incorporar las masas populares a un régimen de bienestar general". Tratou-se aqui de colocar a faculdade de direito no centro de processos de transformação estruturais desejados nos diversos países da América Latina entre os anos sessenta e sessenta. Assim, a reforma no ensino e na pesquisa jurídica tinha uma politics específica influenciando essa reimaginação da faculdade de direito.

Vale ressaltar que os debates realizados durante as conferências de faculdades de direito latino-americanas entre os anos 1959 e 1974 não constituíram o único contexto de discussão sobre ensino jurídico e modernização na região. Nos anos setenta, o movimento que ficou conhecido como direito e desenvolvimento envolveu intensa relação entre professores estadunidenses e estudantes latino-americanos com foco na reforma no ensino jurídico como condição necessária para o desenvolvimento da região $0^{52}$. Optou-se neste artigo por não explorar as especificidades do movimento do direito e desenvolvimento, eis que já estudado em detalhes por muitos autores ${ }^{53}$. De forma mais importante, debates relacionados às reformas pedagógicas em faculdades de direito são anteriores aos programas estadunidenses relacionados à reforma do ensino jurídico na América Latina. A realização das conferências de faculdades de direito latino-americanas, tal como explorado neste trabalho, ilustram claramente esse ponto. Como menciona Rogelio Pérez-Perdomo:

52 "In the 1970s, the movement was known as law and development. The angle that generated most attention was the effort of professors from the United States who, conscious of the important political role of law studies and of the backwardness and poor state of the law schools, travelled to Latin America as missionaries of the case method and the interdisciplinary study of law. A much greater number of young Latin American professors (especially in Brazil, Chile, Colombia, and Peru) obtained master's degrees and doctorates in law, or in some other way familiarized themselves with the teaching of law in the United States (Lynch 1981: 111; Steiner 1971). A good number of professors began to prepare non-traditional instructive materials and made use of the 'active class', as it was called at that time. A small number were interested in interdisciplinary research. Several of the professors from the United States who participated in the experience considered it a failure, since it did not succeed in changing the Latin American legal culture within a few years, with an investment of approximately five million dollars (Trubek and Galanter 1974". PéreZ-Perdomo, R. Lawyers in Late Twentieth-Century Latin America. In FeLSTINER, W. L.F. (ed.). Reorganisation and Resistance. Legal Professions Confront a Changing World. Oxford-Portland, Hart, 2005, 203.

53 Apenas para ilustrar. Veja-se Dezalay, Y. e Garth, B. G. The Internationalization of Palace Wars. Lawyers, Economists, and the Contest to Transform Latin American States. Chicago-London: The University of Chicago Press, 2002; TrubeK, D. e Galanter, M. Scholars in Self-Estrangement: Some Reflections on the Crisis in Law and Development Studies in the United States, Wisconsin Law Review. V. 4. N. 1, 1974, 1062-1103; KenNedY, D. Law and Development Economics: Toward a New Alliance. In Kennedy, D. e Stiglitz, J. E. Law and Economics with Chinese Characteristics. Institutions for Promoting Development in the Twenty-First Century. Oxford: Oxford University Press, 2013, 19-70; Lacerda, G., Falcão, J. e Rangel, T. (eds.). Aventura e legado no ensino jurídico. Rio de Janeiro: FGV Direito Rio, 2012. 
The view from Latin America is somewhat different. The restlessness for change in legal education predated the presence of scholars from the United States. There was a parallel discussion of the topics considered relevant at the time, and the changes in Latin America continued long after the withdrawal of the American organisations that financed projects and the formal declaration of cessation of the American programmes that Trubek and Galanter's article signified ${ }^{54}$.

Faz toda a diferença revisitar debates sobre planos de ensino mais flexíveis, sobre novos critérios de avaliação, sobre estratégias de ensino ativo, sobre critérios para publicação de pesquisas, quando se compreende o projeto político maior que informa esses movimentos de reforma. Como já mencionado anteriormente, os anos sessenta e sessenta foram marcados por articulações teóricas nas Ciências Sociais na América Latina relacionadas à modernização e ao desenvolvimento e, de forma bastante interessante, o direito não ficou alheio a esse rico contexto intelectual. Fica claro, assim, o uso da expressão pedagogía jurídico-social pelos delegados das conferencias de faculdades de direito latino-americanas.

Um segundo aspecto interessante é a necessidade. Vislumbrada pelos delegados das conferências, de articulação de um pensamento comum entre os juristas latino-americanos. Uma sensibilidade compartilhada seria capaz de mobilizar esses esforços de reforma para a concretização de um projeto de transformação social. Essa sensibilidade compartilhada deveria articular a ideia latino-americana, a ideia regional, presente no vocabulário de direito internacional articulado em nossa região desde o século xIx. Se no passado o direito internacional foi usado por juristas internacionalistas latino-americanos para o reconhecimento de sua condição de países civilizados e, posteriormente, para a própria dissolução do standard europeu de civilização ${ }^{55}$, nos anos sessenta e setenta do século posterior, a sensibilidade latino-americana se articulou de forma diversa. Como já mencionado, conceitos jurídicos caminham no tempo e no espaço, transformando-se, e a ideia regional se articulou de forma específica na segunda metade do século xx na América Latina. O projeto de transformação social e reforma imaginado durante as conferências de faculdades de direito latino-americanas incluía a ideia regional como espaço adequado para se pensar alternativas para a concretização dessa transformação. A identificação de uma história comum, de problemas e desafios comuns, de questões jurídico-pedagógicas comuns, facilitaria o comprometimento desse grupo de juristas com uma nova ideia de faculdade de direito.

A grande questão que se coloca após revisitar esses debates relaciona-se com a possibilidade de nova articulação da ideia regional no contexto atual

54 Pérez-Perdomo. Lawyers in Late Twentieth-Century Latin America, cit., 203-204.

55 BeCKer LorCa, Mestizo International Law, cit. 
de complexidade da América Latina. Problemas estruturais de desigualdade e pobreza se mostram resilientes em nossa região, mesmo com a redução da pobreza verificada na região entre os anos 2010 e $2014^{[56]}$. O direito internacional na contemporaneidade continua produzindo enormes impactos em realidades locais ${ }^{57}$, de forma que esse vocabulário integra esse contexto na América Latina.

Nesse sentido, seria possível re-imaginar o ensino e a pesquisa do direito internacional hoje em nossa região para que tenhamos alguma possibilidade de abrir espaço para um olhar mais crítico para os problemas que enfrentamos? A sensibilidade latino-americana e o direito internacional poderiam novamente se articular conjuntamente em projetos que imaginam a transformação da região no sentido de propiciar um contexto de maior igualdade social, redistribuição de renda e de diminuição da pobreza?

Não há possibilidade de responder a essas perguntas em abstrato. Experiências passadas, ligadas a contextos específicos, tal como buscou ilustrar a narrativa deste trabalho, mostram-nos ao menos que a ideia regional e o campo do direito possibilitaram, ou melhor, abriram espaço para a elaboração de projetos de transformação da realidade em determinados momentos no tempo. Afirma-se que as propostas reformistas articuladas no decorrer das conferências de faculdades de direito latino-americanas tiveram êxito limitado no que tange às transformações pretendidas ${ }^{58}$. Mesmo assim, perguntar-se se a ideia regional poderia ser articulada novamente diante das complexidades contemporâneas da América Latina depende de uma clareza maior sobre quais projetos políticos animariam uma tal re-articulação. Nos anos sessenta e setenta, restou claro que esforços de reforma pedagógica eram influenciados por debates sobre modernização e desenvolvimento. Quais debates, quais questões políticas poderiam motivar uma nova articulação da prática do direito internacional no contexto da América Latina na atualidade? Esse parece-me o esforço mais robusto a ser empreendido atualmente se realmente queremos imaginar abordagens críticas para o direito internacional na América Latina hoje.

Esse trabalho não pretende oferecer respostas finais para tais indagações, mas apenas sublinhar a necessidade de uma reflexão mais aprofundada sobre a complexidade dos desafios enfrentados em nossa região nos dias correntes. O que certamente me parece pouco produtivo é continuar pensando na prática do direito internacional em nossa região nos termos de uma contribuição ao

56 CEPAL, Panorama Social da América Latina, 2015, in: http://repositorio.cepal.org/ bitstream/handle/11362/39964/S1600226_en.pdf?sequence=1\&isAllowed=y

57 Para uma análise recente sobre essa articulação entre local e global. Ver EsLAVA, L. Local Space, Global Life. The everyday operation of International Law and development. Cambridge: Cambridge University Press, 2015.

58 Pérez-Perdomo. Lawyers in Late Twentieth-Century Latin America, cit., 203. 
desenvolvimento progressivo do campo do direito internacional, uma perspectiva que Eslava, Obregón e Urueña denominaram "mirada restringida del imperialismo", ou seja, como se o passado colonial de nossa região não tivesse qualquer implicação na situação presente da América Latina, como se pudéssemos pensar na prática presente do direito internacional a partir da América Latina sem qualquer restrição pretérita ${ }^{59}$. Uma perspectiva mais produtiva para se pensar na conformação de uma perspectiva crítica em direito internacional em nossa região se beneficia do engajamento entre direito e história, pois experiências pretéritas permitem iluminar desafios presentes de forma substantiva, mostrando-nos como o vocabulário do direito internacional pode ser articulado conjuntamente com projetos políticos de transformação social. Essa possibilidade não implica assumir que o vocabulário o direito internacional seria o mais adequado per se para levar-se adiante projetos de transformação. No entanto, retomar discussões pretéritas sobre reformas pedagógicas e modernização da região nos mostram as diversas possibilidades relacionadas à articulação de uma sensibilidade latino-americana em direito internacional orientada para projetos políticos de mudança, algo que extrapola a visão tradicional de desenvolvimento progressivo do campo.

\section{CONSIDERAÇÕES FINAIS}

Este trabalho teve como objetivo revisitar os questionamentos articulados por professores, pesquisadores, estudantes e advogados no âmbito das Conferências de Faculdades de Direito Latino-Americanas realizadas entre 1959 e 1974. Sem buscar empreender uma reconstrução histórica exaustiva desses encontros, este estudo buscou lançar luz em antigas discussões sobre ensino jurídico na América Latina. A busca por uma perspectiva crítica para informar a prática de pesquisadores, professores e alunos de direito internacional na América Latina hoje pode ser enriquecida pelos questionamentos pretéritos sobre o papel do direito em projetos políticos de transformação social. Assim, relembrar como advogados latino-americanos passaram a interrogar seu próprio campo no âmbito de um contexto de intensos debates teóricos nas Ciências Sociais em matéria de modernização da região é empreitada produtiva na busca pela construção de uma abordagem crítica sintonizada com os atuais dilemas latino-americanos de desigualdade estrutural, pobreza e redistribuição de renda.

59 "La postura restringida, o canónica, tiende a concebir al imperialismo como una cuestión del pasado y al derecho internacional contemporáneo como una herramienta técnica. A pesar de las múltiples limitaciones institucionales y asimetrias de poder entre los países, la visión restringida es optimista y entiende al derecho internacional como un orden normativo justo e idóneo para avanzar en la construcción de consensos universales sobre convivencia, seguridad, comercio internacional y el medio ambiente". EsLaVA, OBregón e UrueÑa. Imperialismo $(s)$ y derecho(s) internacional(es): ayer y hoy, cit., 19. 
Não se trata aqui de defender mera retomada ou transplante dessas teorias de modernização para o contexto atual. Em especial, esses debates dos anos sessenta e setenta entre advogados da região, ao reforçar uma sensibilidade latino-americana voltada à modernização da América Latina, mostra-nos a importância de projetos políticos mais explícitos e refletidos relacionados a esforços de reforma do ensino e da pesquisa não só do direito em geral, mas também do direito internacional atualmente. Como mencionado anteriormente, a articulação de uma sensibilidade comum latino-americana coloca ênfase no direito internacional como vocabulário que possibilita a articulação dessa sensibilidade compartilhada na região.

Não se trata aqui somente de "completar" nossos cursos de direito internacional com autores da região. Para além de fazer justiça a esse rico passado de juristas internacionalistas latino-americanos, incluindo seus estudos e publicações em cursos de direito internacional no Brasil, na Colômbia, no Chile etc., deve-se refletir sobre o quê gostaríamos de transformar com uma abordagem latino-americana ao direito internacional. Qual o objetivo de articular uma sensibilidade compartilhada, mais uma vez, em pleno século XXI, para o ensino e a pesquisa de direito internacional? Creio que o intenso e amplo auto-questionamento, tal como fizeram nossos colegas na segunda metade do século passado, parece constituir esforço frutífero nessa busca por uma perspectiva crítica que possa articular os problemas agudos e correntes de nossa região.

\section{REFERÊNCIAS}

American Bar Association. 1949 Proceedings of Section of International and Comparative Law. Part v, General Committee Reports, 5. Horack Survey of Latin American Law Schools, 186-187.

Anghie, A., Koskenniemi, M. e Orford, A. (2016). Imperialismo y derecho internacional. Estúdio preliminar: Eslava, L., Obregón, L. e Urueña, R. Bogotá: Siglo de Hombre Editores, Universidad de los Andes, Pontificia Universidad Javeriana.

Arbelaiz, M. La enseñanza del derecho internacional público. Montevideo: Escuela de Artes y Oficios, 1909.

BeCKer Lorca, A. (2014). Mestizo International Law: A Global Intellectual History 18421933, Cambridge: Cambridge University Press.

BeCKer LorcA, A. (2006). International Law in Latin America or Latin American International Law? Rise, Fall, and Retrieval of a Tradition of Legal Thinking and Political Imagination. Harvard International Law Journal. V. 47. N. 1, 283-305.

Burbano López, G. (2011). La Unión de Universidades de América Latina y el Caribe (Udual) y la autonomía universitaria. Ciencia Política. N. ${ }^{\circ} 12,147-169$. 
CePal. (2015). Panorama Social da América Latina, disponible en: http://repositorio. cepal.org/bitstream/handle/11362/39964/S1600226_en.pdf?sequence=1\&isAllowed=y

Conferencias de Facultades Latinoamericanas de Derecho (Ciencias Jurídicas y Sociales). (1964-1965). Anales de la Facultad de Derecho, cuarta época. V. 4. N. 4.

Crawford, J. e Koskenniemi, M. (2012). Introduction. In Crawford, J. e Koskenniemi, M. (eds.). The Cambridge Companion to International Law. Cambridge: Cambridge University Press, 1-21.

Dantas, S. T. (1978/79). Aula inaugural dos cursos da Faculdade Nacional de Direito, 1955. In Ensino Jurídico. Encontros da UnB, Brasília, UnB, 39-45.

Eslava, L.; Obregón, L. e Urueña, R. (2016). Imperialismo(s) y derecho(s) internacional(es): ayer y hoy. In Anghie, A., Koskenniemi, M. e Orford, A. Imperialismo y derecho internacional. Estúdio preliminar: Eslava, L., Obregón, L., Urueña, R. Bogotá: Siglo de Hombre Editores, Universidad de los Andes, Pontificia Universidad Javeriana, 11-94.

Eslava, L. (2015). Local Space, Global Life. The everyday operation of International Law and development. Cambridge: Cambridge University Press.

Esquirol, J. L. (2006). Alejandro Álvarez's Latin American Law: A Question of Identity. Leiden Journal of International Law. V. 19. N. 4, 931-956.

Esquirol, J. L. Latin America. In Fassbender, B. e Peters, A. (eds.). The Oxford Handbook of the History of International Law. Oxford: Oxford University, 2012, 553-585.

Franca Filho, M. T., Mialhe, J. L. e Job, U. da Silveira (eds.). (2013). Epitácio Pessoa e a codificação do direito internacional. Porto Alegre: Sérgio Antonio Fabris.

Fix-Zamudio, H. (1995). Algunas reflexiones sobre la enseñanza del derecho en México y Latinoamérica. In WitKer V., J. (comp.). Antología de estudios sobre enseñanza del derecho. $2 .^{a}$ ed., México: unam, 77-92.

Horack, H. C. (1950). Legal Education in the Latin-American Republics. Journal of Legal Education. V. 2. N. x, 287-297.

Ocampo López, J. (2006). Darcy Ribeiro: sus ideas educativas sobre la universidad y el proceso civilizatorio de América Latina. Historia de la Educación Latinoamericana. V. 8, 137-160.

Montoya, J. (2010). The Current State of Legal Education Reform in Latin America: A Critical Appraisal. Journal of Legal Education. V. 9. N. 4, 545-566.

Obregón, L. (2009). Latin American international law. In Armstrong, D. (ed.), Routledge Handbook of International Law, Routledge: London-New York, 154-164.

Obregón, L. (2015). ¿Para qué un derecho internacional latinoamericano? In Urueña, R. (comp.). Derecho internacional: poder y límites del derecho en la sociedad global. Bogotá: Universidad de los Andes, 27-60.

ORFord, A. (2016). ¿El passado como derecho o como historia? La relevancia del imperialismo para el derecho internacional moderno. In Anghie, A., KoskenNiemi, M., ORFORD, A. Imperialismo y derecho internacional. Estúdio preliminar: Eslava, L. 
Obregón, L., Urueña, R. Bogotá: Siglo de Hombre Editores, Universidad de los Andes, Pontificia Universidad Javeriana, 191-230.

Orford, A. (2012). In Praise of Description. Leiden Journal of International Law. V. 25. N. 3, 609-625.

Ovalle Favela, J. (1977). Bibliografía. Enseñanza del derecho y sociedad en Latinoamérica. v Conferencia de Facultades y Escuelas de Derecho de América Latina. Boletín Mexicano de Derecho Comparado. V. 10. N. 28-29, 221-228.

Pérez-Perdomo, R. (2009) Desafíos de la educación jurídica latinoamericana en tiempos de globalización. El Otro Derecho. N. 38, 11-28.

Pérez-Perdomo, R. (2006). Latin American Lawyers: A Historical Introduction. Stanford, Stanford University Press.

Pérez-Perdomo, R. (2005). Lawyers in Late Twentieth-Century Latin America. In FelsTiner, W. L. F. (ed.). Reorganisation and Resistance. Legal Professions Confront a Changing World. Oxford-Portland: Hart, 195-236.

Primera Conferencia de Facultades/Escuelas Latinoamericanas de Derecho (Ciencias Jurídicas y Sociales). (1959). Informes. Revista de la Facultad de Derecho de México. V. 9. N. 33-34, enero-junio, 1-455.

Ribeiro, D. (2010). Darcy Ribeiro (depoimento, 1978). Rio de Janeiro: cPDoc.

RibeIro, D. (1971). La universidad latinoamericana. Caracas, Biblioteca de la Universidad Central de Venezuela.

Rodríguez-Garavito, C. (2015) Remapping law and society in Latin America. Visions and topics for a new legal cartography. In Rodríguez-Garavito, C. (ed.). Law and Society in Latin America. A new map. New York, Routledge, 1-20.

Sierra, L. Derecho, cambio social y los juristas en Chile: de la estridencia de los 60 al silencio de hoy. Y(2002). SELA (Seminario en Latinoamérica de Teoría Constitucional y Política) Papers. Paper 13, http://digitalcommons.law.yale.edu/yls_sela/13

Tercera Conferencia de Facultades (Escuelas) de Derecho (Ciencias Jurídicas, Políticas y Sociales) Latinoamericanas. (1964). Facultad de Ciencias Jurídicas y Sociales, Universidad de Chile.

Universidad Nacional Autonóma de México. (1949). El Primer Congresso de Universidades Latinoamericanas. Revista de la Universidad de México. V. 3. N. 34, 1-30.

Veçoso, F. F. Carvalho, Roriz, Ribeiro J. H. e Brito, A. Sanctis (2014). “Seremos julgados": revisitando o debate entre Álvarez e Sá Vianna sobre a regionalização do direito internacional na América Latina. In JubiLut, L. (org.). Direito internacional atual. Rio de Janeiro, Elsevier, 287-315. 